\title{
Obesity Prevention In Urban Settings: Creating Healthy Environments
}

Shari McMahan, PhD, California State University Fullerton, USA

Graciela Amaya, MS, California State University Fullerton, USA

\begin{abstract}
The Center for the Promotion of Healthy Lifestyles and Obesity Prevention, housed in the College of Health and Human Development, at California State University, Fullerton promotes interdisciplinary research and community outreach in areas related to children's health and weight management. Two studies focusing on the built environment are showcased. The first study, "Commuting Patterns and Obesity Risk" demonstrates that students with longer commute times are more likely to have a body mass index (BMI) over 25, which is considered overweight. The second study, "Increasing Physical Activity with a Mobile Physical Activity Unit" turned a parking lot into a playground. This was created to provide children in Santa Ana, one of the densest cities in Orange County, California, a place to play. The built environment can have a profound effect on physical activity and if given the opportunity, is important to address in the design stages for the health of our communities.
\end{abstract}

Keywords: Obesity Prevention; Children’s Health; Physical Activity; Childhood Obesity

\section{INTRODUCTION}

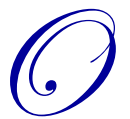

ver the past several years obesity rates for children ages 6 to 11 has more than quadrupled $(4.2 \%$ to $17 \%$ ), and it has more than tripled for adolescents 12 to 19 (from 4.6\% to 17.6\%) (Ogden, Carroll and Flegal, 2008). The dramatic increase in childhood obesity over the past decade has become one of the country's most urgent public health concerns. In Orange County, California, Hispanic/Latino children 0 to 4 and 5 to 11 years old, account to the highest rates of overweight status at 13.9 percent and 22.9 percent (Nguyen, 2009). Hispanic children and adolescents aged twelve to nineteen have the second highest rate at 20.9 percent (Nguyen, 2009). The City of Santa Ana has a childhood obesity rate of $34.8 \%$, which is the second highest rate in the state (Trust for Public Land, 2008).

The Center for the Promotion of Healthy Lifestyles and Obesity Prevention, housed in the College of Health and Human Development, at California State University, Fullerton promotes interdisciplinary research and community outreach in areas related to health and weight management. The Center facilitates interaction among multiple entities concerned with the rise in children's obesity including university faculty, schools, community agencies, and policy makers.

The Center's mission is to:

- work with families, schools and other community agencies to develop and test model health promotion programs and interventions;

- $\quad$ assess and evaluate existing programs and policies;

- identify theoretical models and environments that can explain and influence behavior patterns across different high-risk groups.

As such, the mission and goals of the Center reflect the needs of the community by providing education and outreach to children and their families regarding healthy lifestyles and prevention of obesity. 
The interdisciplinary center at California State University, Fullerton builds upon current research, evaluation and intervention research of faculty and community collaborations in Orange County, focusing particularly on the Latino population. The following two projects offer a comprehensive multi-level approach that will inform the design and implementation of current and future programs that are effective for addressing obesity in children, and adults.

- $\quad$ Project \#1: Commuting Patterns and Obesity Risk

- $\quad$ Project \#2: Increasing Physical Activity with a Mobile Physical Activity Unit

\section{Project 1: Commuting Patterns and Obesity Risk}

Obesity and overweight are now common in American society. College students are at particular risk for gaining weight. The urban environment, because of poor land-use planning, forces college students to become more automobile dependent. Automobile dependency and increased drive time can take away from a more active lifestyle, possibly putting one at risk for adverse health outcomes. A recent publication consisting of 10,878 residents of the 13 county Atlanta regions found time spent in a car as a passenger or driver was positively associated with obesity, and an additional 60 minutes per day in the car translated into an additional 6\% odd of being obese (Frank, Martin, Andresen, \& Schmid, 2004).

A questionnaire regarding commuting patterns, health behaviors and reflections of youth behaviors was created based on review of the existing literature. Students at California State University Fullerton $(n=496)$ enrolled in Personal Health 101 during Fall semester were invited to participate. Course instructors permitted students to complete the 10-15 minute questionnaire during the first 20 minutes of class. Body Mass Index was collected as part of the exercise physiological lab protocol $(\mathrm{N}=361)$. All 496 participants were analyzed except when the outcome was measured with body mass index. Controlling for covariates, the amount of time spent commuting in one's car has an effect on weight. Those who report a drive time of 16 minutes or greater are $64 \%$ more likely to be overweight then those who reported a drive time of 15 minutes or less. Students who reported a drive time of 16 minutes or greater are more likely to consume food in their vehicles $(p<0.013)$. Eating in one's car is highly correlated with fast food consumption $(\mathrm{P}<0.009)$. Most participants perceive commuting as having a slightly or somewhat negative effect on their physical activity (64.4\%). While $7.9 \%$ of participants felt that commuting very much affected their physical activity. Most students $(60.7 \%)$ perceive commuting as having a slightly or somewhat negative effect on their diet and $10.5 \%$ reported that commuting very much so effects their diet.

\section{Project 2: Increasing Physical Activity with a Mobile Physical Activity Unit}

This project was developed to give children who lived in a poorly planned area of Santa Ana, California, access to a "playground" that was non-existent in their neighborhood. A mobile physical activity unit (MPAU), which housed playground equipment, was created with the intent of providing safe, age-appropriate and supervised activities and games. A collaboration resulting in a joint-use agreement was established between Latino Health Access and St. Joseph's Catholic School. The joint-use agreement allowed access to the schools parking lot twice a week for 12 weeks, to host the games and physical activities for the participating children and thus creating a playground, where a playground did not exist.

A total of 24 children and their families participated in the study. The selection of the participants was done by a non-random area sampling of families with children ages 6-14 years old living in the 92701 zip code of Santa. Both quantitative and qualitative measures were selected to gain a better understanding of the barriers, aesthetics, proximity and availability of parks, open spaces or green belts in the 92701 zip code of Santa Ana and the time it takes to walk to the nearest physical activity amenity. Throughout the 12 week program, brief informal interviews were conducted with the parents and children to hear feedback about the project and its impact.

The MPAU was driven to St. Joseph's school every Tuesday evening from $4 \mathrm{pm}$ to $6 \mathrm{pm}$ and Saturday mornings from $10 \mathrm{am}$ to $12 \mathrm{pm}$, for a total of 12 weeks. Once the orientation was completed, the children were assigned into one of two age groups, which were broken down into 6-10 and 11-14 years old, for the remainder of the 12 weeks. A total of 3 different games and/or activities were selected and supervised by the research team and 
volunteers. In addition to the 3 games and/or activities, a total of 30 minutes were dedicated to "free play", where the children were able to create and play games on their own, utilizing the playground equipment that was housed within the MPAU.

The inspiration for the MPAU came from an observation made at another physical activity project conducted by CSUF, named "Active Kids." The children of that program while waiting for their parents ran as fast they could to the ice-cream truck, which was passing by. The idea of a mobile unit which brought the same joy and happiness to the children was born. But the difference was that this mobile unit would bring fun games to their neighborhoods, rather than candy, chips and sugary drinks.

The children participating in the MPAU also had very positive and encouraging comments about their desire to play and be physically active. Many of the children wanted the project to be held seven days a week instead of two and some of the parents also expressed this feeling.

Comments from several parents during the informal interviews were very moving and clearly demonstrated the need for this kind of projects in areas where there are very limited open spaces and/or parks. One parent in particular said that she no longer worried about her child when they came to participate in the MPAU. Her worry came from an incident where here child was hit by a passing car in front of her home where her child would normally play. Other parents also expressed their feelings about the healthy and safe environment provided by the MPAU project and how the university volunteers, who assisted in the development and implementation of the physical activities, served as great role models to their children.

The research projects illustrated above demonstrate the importance of the built environment as an approach to prevent obesity. Successful programs must include environmental and policy strategies to be effective.

\section{AUTHOR INFORMATION}

Shari McMahan, Ph.D., MCHES - Dr. Shari McMahan is Dean of the College of Health and Human Development at California State University Fullerton and Director for the Center for the Promotion of Healthy Lifestyles and Obesity Prevention. Her research utilizes a social ecological approach in the prevention of obesity and has been awarded $\$ 1,000,000.00$ in research grants to promote healthy lifestyles. Dr. McMahan is a Masters Level prepared Certified Health Education Specialist and past Vice President of Health and Research divisions for the Southwest District of the American Alliance for Health, Physical Education, Recreation and Dance. Contact Information: Center for the Promotion of Healthy Lifestyles and Obesity Prevention and College of Health and Human Development, California State University Fullerton, 800 N. State College Blvd EC-606, Fullerton, Ca. 92834 USA. E-mail: smcmahan@ fullerton.edu (Corresponding author)

Graciela Amaya, MS - Graciela Amaya, is an Assistant for the Health Promotion Research Institute, Center for Successful Aging, and the Center for Healthy Lifestyles and Obesity Prevention at California State University, Fullerton. Her research interests are working with the community health needs of older adults and children to promote health and well-being. She has over 10 years experience assisting faculty in the departments of Kinesiology and Health Science with research grants ranging from obesity research, fall prevention, fibromyalgia, and cancer related research. Contact information: Center for the Promotion of Healthy Lifestyles and Obesity Prevention and College of Health and Human Development, California State University Fullerton, 800 N. State College Blvd EC-606, Fullerton, Ca. 92834 USA. E-mail: gamaya @ fullerton.edu

\section{REFERENCES}

1. Babey, S. H., Hastert, T. A., Yu, H., \& Brown, E. R. (2008). Physical activity among adolescents When do parks matter? American Journal of Preventive Medicine, 34(4), 345-348.

2. Black, J. L., \& Macinko, J. (2008). Neighborhoods and obesity. Nutrition Reviews, 66(1), 2-20. Flores, G. R. (2008). Active living in Latino communities. American Journal of Preventative Medicine, 34 (4), 369370 . 
3. Booth K.M., Pinkston M.M., Poston W.C. (2005). Obesity and the built environment. Journal of the American Dietetic Association, 105, S110-117.

4. Centers for Disease Control and Prevention (2005). Overweight and obesity: defining overweight and obesity. Retrieved May15, 2005, from http://www.cdc.gov/nccdphp/dnpa/obesity/defining.htm

5. Centers for Disease Control and Prevention (2005). Overweight and obesity: obesity trends: U.S. obesity trends 1985-2004. Retrieved May 15, 2005, from

http://www.cdc.gov/nccdphp/dnpa/obesity/trend/maps/index.htm

6. Davis H., Gergen PJ. (1994). The weights and heights of Mexican American adolescents. American Journal of Public Health, 84, 459-46.

7. Douglas K.A., Collins J.L. (1997). Results from the 1995 national college risk survey. Journal of American College Health, 46, 55-67.

8. $\quad$ Fahlman M., Hall H., Lock R. (2006). Ethnic and socioeconomic comparisons of fitness, activity levels, and barriers to exercise in high school females. Journal of School Health, 76, 12-17.

9. $\quad$ Frank L. D., Anderesen M., Schmid T.L. (2004). Obesity relationships with community design, physical activity and time spent in cars. American Journal of Preventative Medicine, 27, 87-96.

10. Garcia, R., Bracho, A., Cantero, P., \& Glenn, A.G. (2009) "Pushing” physical activity, and justice. Preventitive Medicine, 49(4), 330-333.

11. Gómez, J. E., Johnson, B. A., Selva, M., \& Sallis, J. F. (2004). Violent crime and outdoor physical activity among inner-city youth. Preventive Medicine, 39(5), 876-881.

12. Handy SL, Boarnet MG, Ewing R, Killingsworth RE. (2002). How the built environment affects physical activity: Views from urban planning. American Journal of Preventative Medicine, 23, 64-73.

13. Health Eating, Active Communities-Santa Ana. (2010.). Community Description. Retrieved April 10, 2010 , from http://www.healthyeatingactivecommunities.org/grantee_showcase1_4.php

14. Henderson, K. A., \& Bialeschki, M. D. (2005). Leisure and active lifestyles: Research reflections. Leisure Sciences, 27(5), 355-365.

15. Knutson B.J. (2000). College students and fast food-how students perceive Restaurant Brands. Cornell Hotel and Restaurant Administration Quarterly, 41, 68-74.

16. Levin, S., and Martin, M. (2002). Catch the Catawba SPARK: Physical activity for head start youths. Journal of Physical Education Recreation and Dance 73 (3) 39-42.

17. Lopez R. (2004). Urban sprawl and the risk of being overweight or obese. American Journal of Public Health, 94, 1574-1585.

18. Maddock J. (2004). The relationship between obesity and the prevalence of fast food restaurant: state-level analysis. American Journal of Health Promotion, 19, 137-143.

19. McKenzie, T.L., Nader, P.R., Strikmiller, P.K., Yang, M., Stone E.J. (1996). School physical education: Effect of the child and adolescent trial for cardiovascular health (CATCH). Preventive Medicine 25:423431.

20. Nguyen, J. (2009). The $15^{\text {th }}$ Annual Report On The Conditions Of Children In Orange County [PowerPoint slides]. Retrieved from Orange County Health Info website: http://www.ochealthinfo.com/cscc/report/

21. Nielson S.J., Siega-Ritz A.M., Popkin BM. (2002). Trends in food locations and sources among adolescents and young adults. Preventative Medicine, 35, 107-113.

22. O’Connell, K. (2009, July, 17). Fitness On Wheels. Retrieved May 6, 2010, from The Fun Bus website: http://www.funbuses.com/press/Gloucester Times.htm

23. Ogden C., Carroll M., Lester R., McDowell M., Tabak C., Flegal K. (2006). Prevalence of overweight and obesity in the United States, 199-2004. Journal of the American Medical Association, 295, 1549-1555.

24. Ogden, C., Carroll M, and Flegal, K. (2008) High body mass index for age among US children and adolescents, 2003-2006. Journal of the American Medical Association, 299 (20):2401-2405.

25. Paeratakul S., Ferdinand D.P., Champane C.M., Ryan D.H, Bray G.A. (2003). Fast-Food consumption Among US adults and children: Dietary and nutrient Intake Profile. Journal of American Dietitians Association, 103, 1332-1338.

26. Pereira M. A., Kartashov A. I. , Ebbeling C. B., Van Horn L., Slattery M. L., Jacobs D.R., Ludwig D. (2005). Fast-food habits, weight gain, and insulin resistance (the CARDIA study): A 15-year analysis. The Lancet, 365, 36-42. 
27. Racette S. B., Deusinger S. S., Strube M. J., Highstein G. R., Deusinger R. H. (2005). Weight changes, exercise, and dietary patterns during freshman and sophomore years of college. Journal of American College Health, 53, 245-251.

28. Saelens B. E., Sallis J. F., Frank L. D. (2003). Environmental correlates of walking and Cycling: Findings from the transportation, urban design, and planning literatures. Annals of Behavioral Medicine, 25, 80-91.

29. Stokols, D. (1996). Translating social ecological theory into guidelines for health promotion. American Journal of Health Promotion, 10, 282-298.

30. Roemmich, J. N., Epstein, L. H., Raja, S., Yin, L., Robinson, J., \& Winiewicz, D. (2006). Association of access to parks and recreational facilities with the physical activity of young children. Preventive Medicine, 43(6), 437-441.

31. The Trust For Public Land Conservation Vision Program. (2008). The Trust for Public Land. Oakland, CA.

32. Veitch, J., Salmon, J., \& Ball, K. (2007). Children's perceptions of the use of public open spaces for active free-play. Children's Geographies, 5(4), 409-422.

33. Weir, L. A., Etelson, D., \& Brand, D. A. (2006). Parents' perceptions of neighborhood safety and children's physical activity. Preventive Medicine, 43(3), 212-217. 


\section{NOTES}

